\title{
miR-218 inhibits the proliferation of glioma U87 cells through the inactivation of the CDK6/cyclin D1/p21 ${ }^{\text {Cip1/Wafl }}$ pathway
}

\author{
GU JIAN JUN ${ }^{1 *}$, GAO GUANG ZHONG ${ }^{1 *}$ and ZHANG SHI MING ${ }^{2}$ \\ ${ }^{1}$ Department of Neurosurgery, Taizhou People's Hospital, Taizhou, Jiangsu 225300; \\ ${ }^{2}$ Department of Neurosurgery, The First Affiliated Hospital of Soochow University, Suzhou, Jiangsu 215006, P.R. China
}

Received June 9, 2014; Accepted March 16, 2015

DOI: 10.3892/ol.2015.3068

\begin{abstract}
Malignant gliomas are the most common and deadly primary brain tumors in adults and the high proliferative ability of these cells is one of the most important causes of the poor prognosis of this cancer. Suppressing the proliferation of malignant gliomas cells by altering effector molecules can significantly improve the prognosis of a patient. microRNAs (miRNAs) are small non-coding RNA molecules 22 nucleotides in length that are able to function as oncogenes or tumor suppressors in human cancer. In the present study, it was demonstrated that the expression level of miRNA-218 (miR-218) is markedly downregulated in glioma cell lines and human primary glioma tissues. Upregulation of miR-218 in glioma U87 cells dramatically inhibited the proliferation by inducing $\mathrm{G}_{1}-\mathrm{S}$ checkpoint arrest. Furthermore, it was demonstrated that ectopically expressing miR-218 in glioma U87 cells results in the downregulation of the expression of cyclin dependent kinase (CDK)6 and cyclin D1 and upregulation of the expression of $\mathrm{p} 21^{\mathrm{Cip} 1 / \mathrm{Waf} 1}$. In addition, it was identified that miR-218 inactivated the CDK6/cyclin D1/p21 Cip1/Waf1 pathway by downregulating CDK6 expression through the direct targeting of the 3'-untranslated region of CDK6. The present results suggest that miR-218 plays an important role in the prevention of the proliferation of glioma cells, and the present study also revealed a novel mechanism for miRNA-mediated direct suppression of the CDK6/cyclin D1/p21 Cip1/Waf1 $^{\text {pathway }}$ in glioma cells.
\end{abstract}

\section{Introduction}

Human glioma is the most common primary tumor in the central nervous system and is characterized by a high

Correspondence to: Mr. Gu Jian Jun, Department of Neurosurgery, Taizhou People's Hospital, 399 Hailing South Road, Taizhou, Jiangsu225300, P.R. China

E-mail: gujianjundt@163.com

*Contributed equally

Key words: miR-218, gliomas, proliferation, CDK6, cyclin D1, p21 Cip1/Wafl proliferative and invasive ability (1). Standard therapies for glioma, including surgery, radiation and chemotherapy, are only effective in treating patients with a high-grade condition. Numerous glioma patients have already developed metastasis at the onset of clinical symptoms (2). The mechanism of glioma tumorigenesis remains unclear, and the molecular determinants of the aggressiveness of glioma have been the subject of numerous studies, but these investigations have not yet reached full fruition (3-6). Therefore, there is an acknowledged requirement for novel approaches based on increased understanding of the biological and molecular nature of these tumors.

microRNAs (miRNAs) are shortnon-coding, single-stranded RNA molecules that are 22-25 nucleotides in length and negatively regulate gene expression by post-transcriptional silencing of target messenger RNAs (mRNAs) through complementary binding $(7,8)$. An increasing number of studies have indicated that miRNA plays an important role in the development of various cancers, including glioma, and miRNA has been associated with tumor suppressor and oncogenic activities $(9,10)$. Out of these miRNA molecules, miRNA 218 (miR-218) has been revealed to be downregulated in human glioblastoma multiforme (GBM) specimens compared with the adjacent brain tissue that is devoid of tumor cells (11-14). Accumulated data have demonstrated that the upregulation of miR-218 is able to inhibit tumor cell invasion and proliferation in glioma cells by altering the expression of multiple target genes (14-17).

In the present study, the expression of miR-218 was upregulated by transient transfection of the human glioma U251, U87, SNB19 and LN229 cells with miR-218 mimics. This was performed with the aim of affecting the cyclin dependent kinase (CDK)6/cyclin D1/p21 $1^{\text {Cip1/Waf1 }}$ pathway and demonstrating that miR-218 inactivates the CDK6/cyclin D1/p21 ${ }^{\text {Cip1/Waf1 }}$ pathway by directly targeting the 3'-untranslated region (UTR) of CDK6. Furthermore, it was not only found that the stable expression of miR-218 inhibited proliferation in vitro and suppressed tumorigenicity of glioma cells in vivo, but it was also found that the expression of CDK6 and cyclin D1 in xenograft tumor tissues was significantly decreased, in contrast to the expression of $\mathrm{p} 21^{\text {Cip1/Waf1 }}$, which was significantly increased. In summary, the present results suggest that miR-218 inhibits the proliferation of glioma cells through the inactivation of the CDK6/cyclin D1/p21 Cip1/Waf1 signaling pathway. 


\section{Materials and methods}

Clinical samples. Tumor specimens were obtained from patients that underwent positive debulking surgery in the Neurosurgery Department of The First Affiliated Hospital of Soochow University (Suzhou, China) between 2011 and 2013. The diagnosed gliomas were reviewed on histological slides by an experiential neuropathologist, according to the 2007 World Health Organization classification (18), resulting in 20 glioma samples being classified as grades I and II, 20 as grade III and 20 as grade IV. In total, 10 normal brain tissue samples were obtained from the internal decompression of patients with cerebral injury. For the use of these clinical materials for research purposes, patient consent and approval from the Ethics Committee of Taizhou People's Hospital (Taizhou, China) and The First Affiliated Hospital of Soochow University was obtained prior to the present study.

Cell lines and transfection. Primary normal human astrocytes (NHAs) were purchased from Sciencell Research Laboratories (Carlsbad, CA, USA). The glioma U251, U87, SNB19 and LN229 cell lines were obtained from the Institute of Biochemistry and Cell Biology, Chinese Academy of Sciences (Beijing, China). The cells were maintained in RPMI-1640 medium (Invitrogen, Carlsbad, CA, USA) containing 10\% fetal bovine serum, 50 units $/ \mathrm{ml}$ penicillin $\mathrm{G}$ and $250 \mu \mathrm{g} / \mathrm{ml}$ streptomycin (Invitrogen) in a humidified atmosphere containing 5\% $\mathrm{CO}_{2}$ at $37^{\circ} \mathrm{C}$. Transfections with miR-218 were performed in serum-free medium $24 \mathrm{~h}$ subsequent to plating, using Lipofectamine 2000 (Invitrogen). After $6 \mathrm{~h}$, the cells were placed in complete medium and maintained at $37^{\circ} \mathrm{C}$ in a $5 \% \mathrm{CO}_{2}$ atmosphere.

RNA extraction and reverse transcription quantitative polymerase chain reaction ( $R T-q P C R)$. Total RNA, including miRNA, was extracted from cultured cells or fresh glioma cancer tissues using TRIzol reagent (Invitrogen), according to the manufacturer's instructions. The expression of miR-218 was quantified using the miRNA-specific TaqMan miRNA Assay kit (Applied Biosystems Life Technologies, Foster City, CA, USA). U6 small nuclear RNA was used as an internal control. The mRNA expression of CDK6, cyclin D1 and p21 $1^{\text {Cip//Wafl } 1}$ was analyzed by qPCR using the SYBR-Green method (7500 ABI; Applied Biosystems Life Technologies). The protocols were performed according to the manufacturer's instructions and the results were normalized to the expression of GAPDH. The primers used were as follows: CDK6 forward, 5'-CTGAAT GCTCTTGCTCCTTT-3' and reverse, 5'-AAAGTTTTGGTG GTCCTTGA-3'; cyclin D1 forward, 5'-TCCTCTCCAAAA TGCCAGAG-3' and reverse, 5'-GGCGGATTGGAAATG AACTT-3'; p21 forward, 5'-CGATGCCAACCTCCTCAA CGA-3' and reverse, 5'-TCGCAGACCTCCAGCATCCA-3'; and GAPDH forward, 5'-TCGGAGTCAACGGATTTGG-3' and reverse, 5'-CATGGGTGGAATCATATTGGA-3'.

Western blotting. Cells were lysed using $1 \%$ nonidet P-40 lysis buffer $48 \mathrm{~h}$ subsequent to exposure of the cells to LY294002 or vehicle treatment. Homogenates were clarified by centrifugation at $20,000 \mathrm{xg}$ for $15 \mathrm{~min}$ at $4^{\circ} \mathrm{C}$, and the protein concentrations were determined using a bicinchoninic acid protein assay kit
(Pierce Biotechnology, Inc., Rockford, IL, USA). SDS-PAGE was performed on $40 \mu \mathrm{g}$ of protein from each sample. The gels were then transferred to polyvinylidene difluoride membranes (EMD Millipore, Billerica, MA, USA) and incubated with polyclonal rabbit anti-human CDK6 (dilution, 1:200; cat. no. sc-177; Santa Cruz Biotechnology, Inc., Dallas, TX, USA), polyclonal mouse anti-human cyclin D1 (dilution, 1:200; cat. no. sc-29287; Santa Cruz Biotechnology, Inc.) and polyclonal mouse anti-human p21 Cip1/Waf1 (dilution, 1:100; cat. no. sc-44271; Santa Cruz Biotechnology, Inc.) primary antibodies, which was followed by incubation with horseradish peroxidase-conjugated monoclonal goat anti-rabbit or anti-mouse IgG secondary antibodies (dilution, 1:1,000; cat. no's. W10804 and W10815; Zymed Life Technologies, Carlsbad, CA, USA). The membranes were stripped and reprobed with a primary polyclonal mouse anti-human GAPDH antibody. The protein bands were quantitated by densitometry using the gel analysis ImageJ software (National Institutes of Health, Bethesda, MA, USA). The values were normalized to the expression of GAPDH (dilution, 1:1,000; cat. no. sc-48167; Santa Cruz Biotechnology, Inc.).

Luciferase assay. The CDK6 3'-UTR sequence that was predicted to interact with miR-218 and a mutated sequence containing the predicted target sites were synthesized and inserted into the $X b a \mathrm{I}$ and FseI sites of a pGL3 control vector (Promega, Madison, WI, USA). These constructs were termed pGL3-CDK6-3'UTR and pGL3-CDK6-3'UTR-mut. For the reporter assay, the U87 cells were plated onto 24-well plates and transfected with pGL3-CDK6-3'UTR or pGL3-CDK6-3'UTR-mut, and P-miR-218 or P-miR-control vectors using FuGENE HD (Promega, Madison, WI, USA). A Renilla luciferase vector, pRL-SV50 (Promega), was cotransfected to normalize the differences in transfection efficiency. Subsequent to transfection for $48 \mathrm{~h}$, the cells were harvested and assayed using the Dual-Luciferase Reporter Assay system (Promega) according to the manufacturer's instructions. Transfection was repeated three times in triplicate.

Proliferation assay. The proliferative ability of cells was measured by using the cell counting kit-8 (CCK-8) at 24 , 48 and $72 \mathrm{~h}$ post-transfection, according to the manufacturer's protocol. Briefly, $10 \mu 1$ of CCK-8 solution was added to each well. Following incubation at $37^{\circ} \mathrm{C}$ for $4 \mathrm{~h}$ in $5 \% \mathrm{CO}_{2}$, the absorbance of each well at a wavelength of $490 \mathrm{~nm}$ was detected using a microplate reader (Multiskan Spectrum; Thermo Fisher Scientific, Inc., Waltham, MA, USA).

Clonogenicity assay. The stably-transfected glioma cells were seeded into six-well plates and cultured in cell culture medium for two weeks to allow colony formation. The culture medium was changed every third day. The colonies were then fixed in $100 \%$ methanol and stained with crystal violet solution. Subsequently, the number of macroscopically observable colonies was recorded.

Cell cycle assay. The cells were harvested by trypsinization $48 \mathrm{~h}$ subsequent to transfection, washed three times with ice-cold phosphate-buffered saline (PBS), and fixed with $70 \%$ ethanol overnight at $4^{\circ} \mathrm{C}$. The fixed cells were rehydrated in PBS and subjected to propidium iodide/RNase staining 

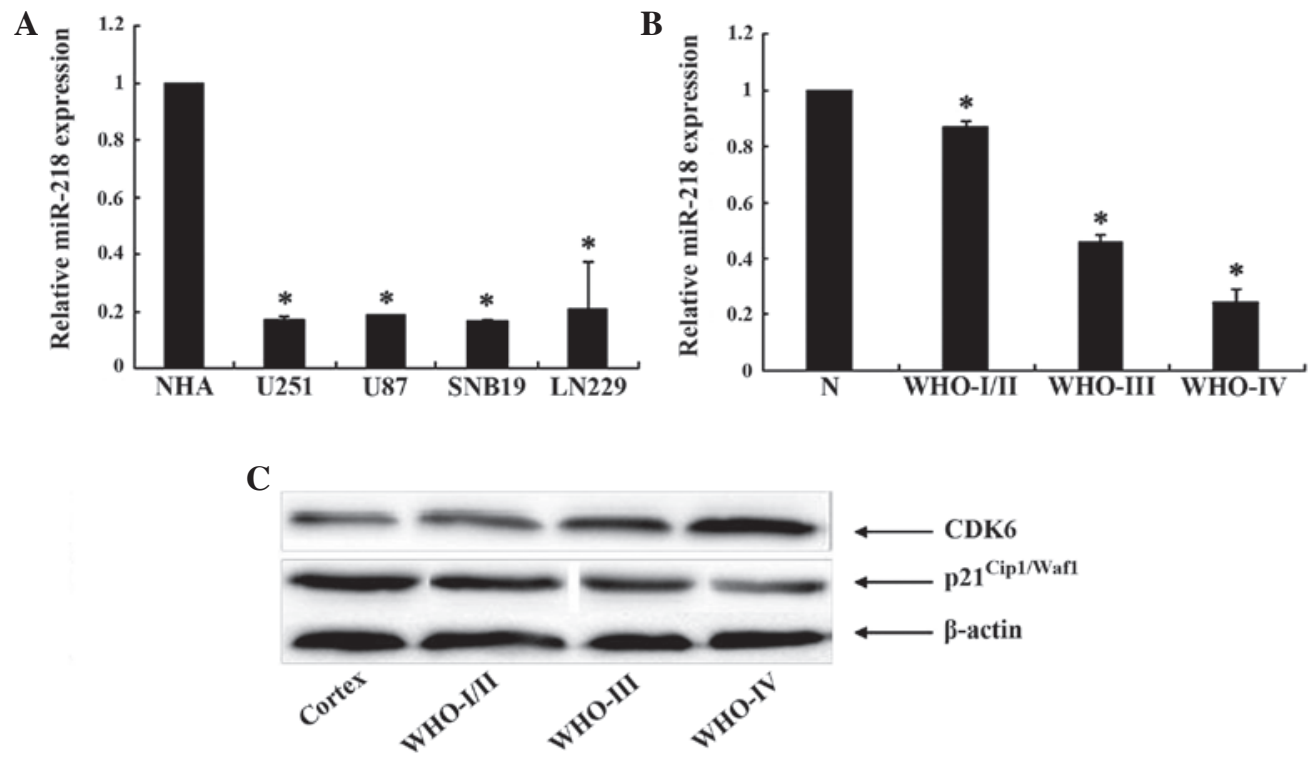

Figure 1. Level of miR-218 expression in glioma cell lines and tissues, and the expression of miR-218 and CDK6 in glioma tissues. (A) Expression of miR-218 was detected in the glioma U251, U87, SNB19 and LN229 cell lines and in the primary NHAs. (B) miR-218 was detected in 10 normal brain tissue and 60 glioma tissues by quantitative polymerase chain reaction. (C) Expression of CDK6 and p21 $1^{\mathrm{Cip} / \mathrm{Wafl}}$ was detected by western blot analysis. The data are expressed as the mean + standard deviation of three independent experiments. " $\mathrm{P}<0.05$ vs. NHAs. NHAs, normal human astrocytes; WHO, World Health Organization; CDK6, cyclin dependent kinase; miR-218, microRNA-218.

followed by fluorescence-activated cell sorter scan (FACS) analysis (Becton Dickinson, Mountain View, CA, USA). The percentage of cells in each phase of the cell cycle was estimated using PV ELITE software (Integraph Corporation, Madison, AL, USA).

Animal studies. Stably transfected U87 cells were resuspended in PBS and implanted into the left flanks of the $\mathrm{BALB} / \mathrm{c}$ athymic mice, with $1.5 \times 10^{6}$ cells being administered per flank by subcutaneous injection. The tumor volumes were determined by measuring the length $(a)$ in $\mathrm{mm}$, and the width (b) in $\mathrm{mm}^{3}$, of the mass. The tumor volume (V) was calculated according to the formula $\mathrm{V}=a b^{2} / 2$. The statistical significance of the difference between the P-miR-218 and P-miR-control transfected groups was evaluated using Student's $t$-test. All procedures that involved animals were performed according to the guidelines of The First Affiliated Hospital of Soochow University, Soochow University and Chinese Academy of Medical Sciences.

Statistical analysis. Experimental data were presented as the mean \pm standard deviation. All statistical analyses were performed using a two-tailed Student's $t$-test performed by SPSS software, version 12.0 (SPSS, Inc., Chicago, IL, USA). $\mathrm{P}<0.05$ was considered to indicate a statistically significant difference.

\section{Results}

miR-218 is downregulated in glioma tissues. To analyze the expression levels of miR-218, qPCR was performed to assess miR-218 expression in the glioma U251, U87, SNB19 and LN229 cell lines. The results revealed that miR-218 was downregulated in all glioma cell lines compared with the NHAs $(\mathrm{P}<0.05)$. In addition, when miR-218 expression was measured in 10 normal brain and 60 glioma tissue samples, the expression level of miR-218 was observed to be significantly decreased in glioma tissues, particularly in grade III/IV tissues (Fig. 1A and B). This result demonstrated that miR-218 expression decreases markedly from normal brain tissue to low-grade to GBM tissue. Overall, the present results indicate that miR-218 was downregulated in glioma cell lines and glioma tissues.

CDK6 is upregulated and $p 21^{\text {Cipl/Wafl }}$ is downregulated in glioma tissues. The expression levels of CDK6 and $\mathrm{p} 21^{\text {Cip } 1 / \text { Waf } 1}$ were identified in glioma tissues using western blot analysis, and it was observed that CDK6 was expressed at extremely low levels in normal brain tissue, but at extremely high levels in human glioma tissues. In addition, with the progression of malignant glioma, the expression of CDK6 is gradually increased. By contrast, p21 $1^{\text {Cip1/Waf1 }}$ was expressed at very high levels in normal brain tissue, but at very low levels in human glioma tissues (Fig. 1C).

Upregulation of miR-218 regulates expression of CDK6/cyclin D1/p21 Cip1/Wafl in glioma U87 cells. In the present study, the possibility that cell cycle regulators may be modulated by miR-218 was investigated. Quantitative PCR analysis revealed that treatment with the miR-218 mimic for $24 \mathrm{~h}$ significantly upregulated the mRNA levels of $\mathrm{p} 21^{\mathrm{Cip} 1 / \text { Waf1 }}$, followed by a decrease in the expression of CDK6 and cyclin D1 (Fig. 2A-C). Notably, western blot analysis revealed similar results to the quantitative PCR analysis by miR-218 overexpression (Fig. 2D). Overall, these results indicated that miR-218 is able to transcriptionally regulate the expression of CDK6, cyclin D1 and p21.

CDK6 is a functional downstream target of miR-218. Using the publicly available algorithms in TargetScan (Whitehead 
A
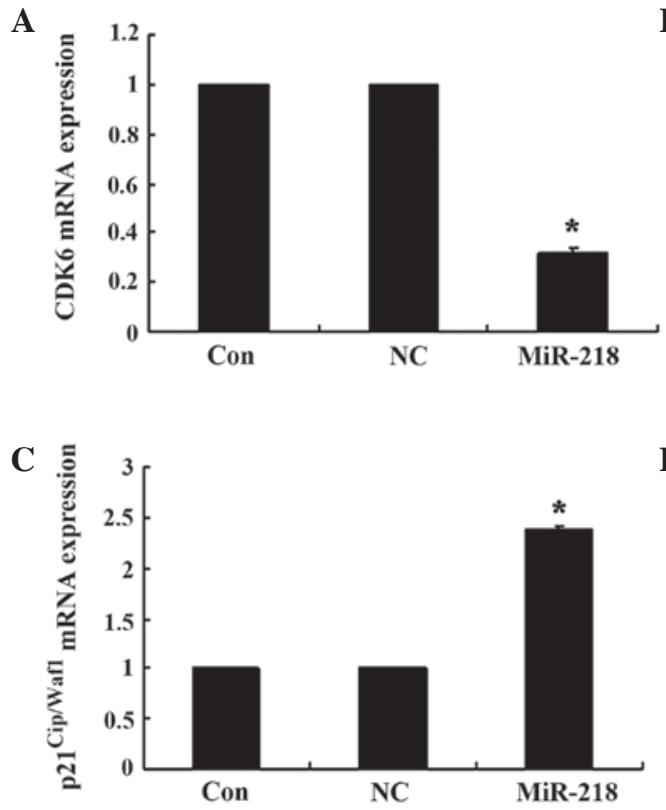

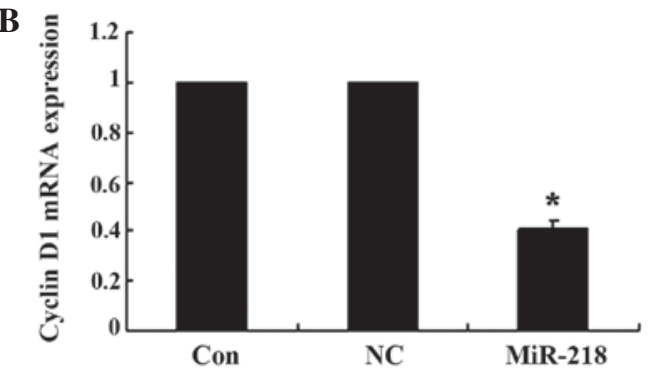

D

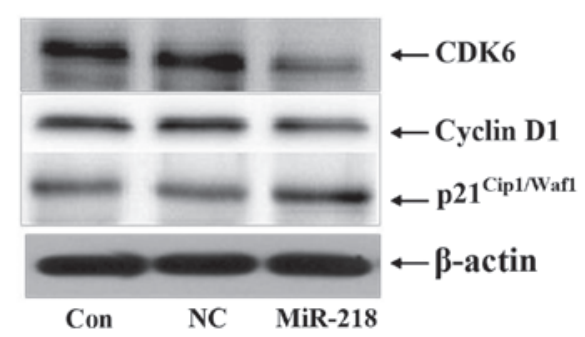

Figure 2. Upregulation of miR-218 reduces CDK6 expression through the inactivation of the CDK6/cyclin D1/p21 Cipl/waf1 pathway. (A-C) The U87 cells were treated with control, $\mathrm{NC}$ and miR-218 mimics, and the levels of CDK6, cyclin D1 and p21 $1^{\mathrm{Cip} / \mathrm{Waf1}} \mathrm{mRNA}$ were measured by quantitative polymerase chain reaction. (D) The levels of the CDK6, cyclin D1 and $\mathrm{p} 21^{\mathrm{Cip} / \mathrm{Waf} 1}$ proteins in the U87 cells were measured by western blot analysis. The data are expressed as the mean + standard deviation of three independent experiments. "P<0.05 vs. control. CDK6, cyclin dependent kniase 6; miR-218, microRNA-218; Con, control, NC, negative control.

A Human CDK6 3'UtR: 5'...UAUgaAgaAaAaUdaAagcacaA....3"
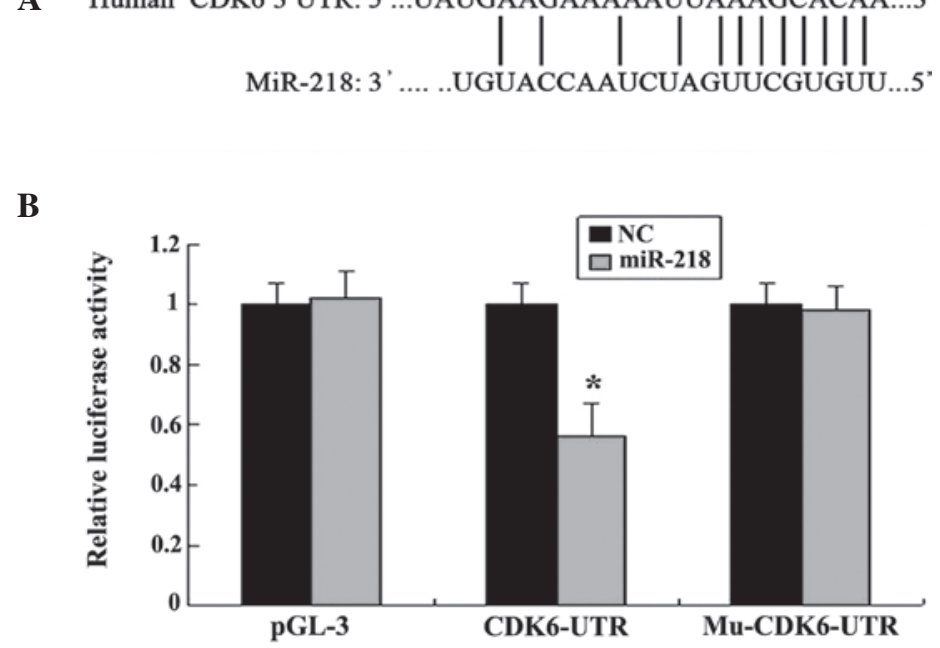

Figure 3. CDK6 is a direct target of miR-218. (A) Identification of target sites in the 3'-UTR of CDK6 was performed in TargetScan. (B) A luciferase assay was performed to determine the targeting association in the U87 cells. The data are expressed as the mean + standard of three independent experiments."P<0.05 vs. control. CDK6, cyclin dependent kinase 6; miR-218, microRNA-218; NC, negative control; UTR, untranslated region.

Institute for Biomedical Research, Cambridge, MA, USA), CDK6 was theoretically identified as the target gene of miR-218 (Fig. 3A). A luciferase reporter assay further confirmed the direct association between miR-218 and the 3'-UTR of CDK6 mRNA. The luciferase activity for the wild-type 3'-UTR of CDK6 was significantly inhibited by cotransfection with miR-218 mimics compared with constructs containing mutated 3'-UTRs. This demonstrated that CDK6 is a direct target of miR-218 (Fig. 3B).

Upregulation of miR-218 inhibited cell proliferation in U87 cells. To determine the effects of miR-218 on glioma cell proliferation in vitro, cell proliferation and plate clonogenic assays were used. As shown in Fig. 4A, the cell growth inhibition rate was evidently increased in the miR-218 mimic group compared with the control groups at 48 and $72 \mathrm{~h}$ post-transfection $(\mathrm{P}<0.05)$. In Fig. $4 \mathrm{~B}$ and $\mathrm{C}$, stable overexpression of miR-218 markedly reduced the number of surviving colonies from the U87 cell line compared with the control and $\mathrm{NC}$ groups $(\mathrm{P}<0.05)$. This finding indicates that miR-218 is able to significantly inhibit the proliferation of glioma cells. Consequently, a cell cycle analysis was conducted in the U87 cells transiently transfected with the miR-218 mimics. The results revealed that the cells 

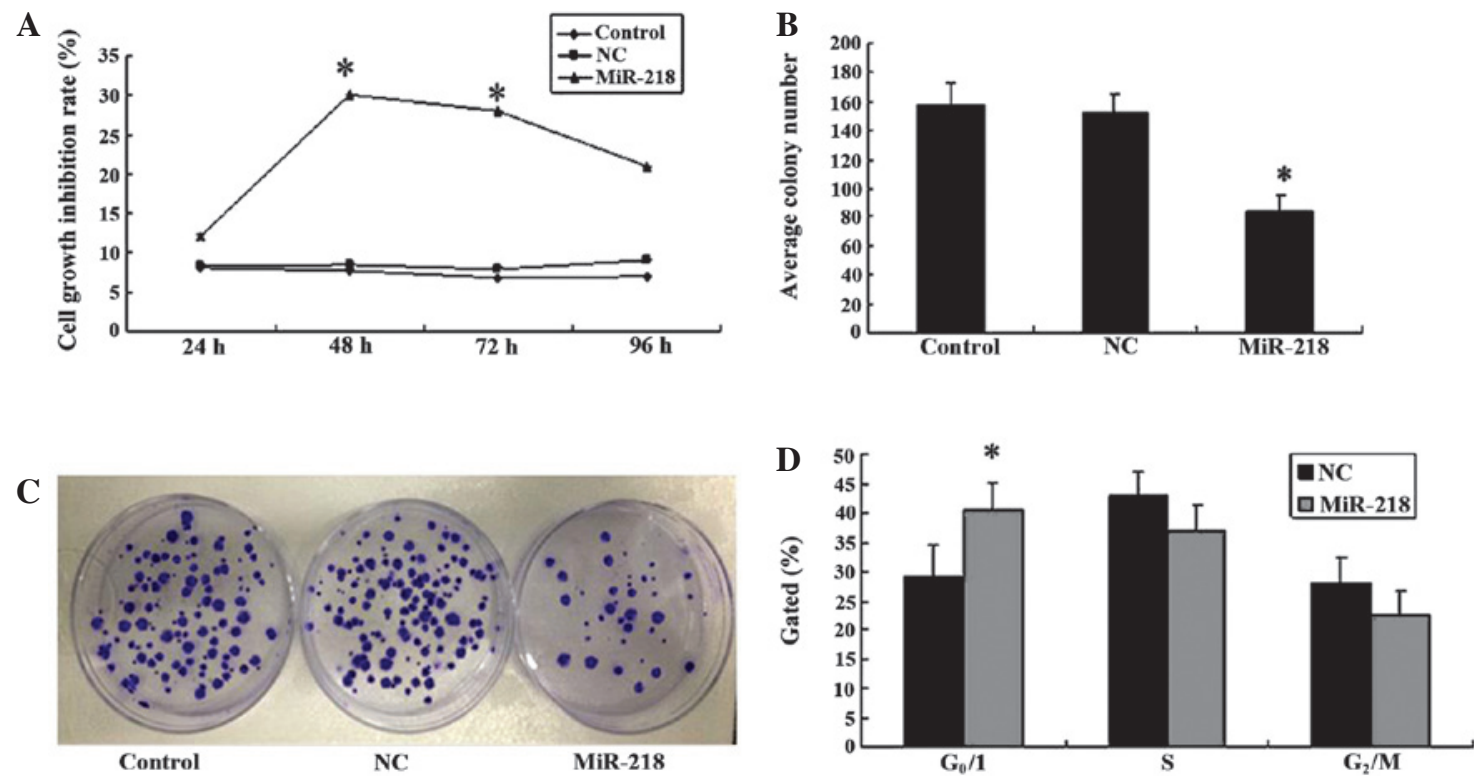

Figure 4. miR-218 inhibits cell proliferation in U87 cells. (A) miR-218 significantly inhibited the proliferation of U87 glioma cells at various time points. (B and C) Upregulation of miR-218 dramatically reduced the number of surviving colonies from the U87 cell lines compared with the control and NC groups. (D) Upregulation of miR-218 resulted in an increased accumulation at the $\mathrm{G}_{0}-\mathrm{G}_{1}$ phase with a decreased accumulation at the $\mathrm{S}$ phase. The data are the mean + standard deviation of three independent experiments. "P<0.05 vs. control. miR-218, microRNA-218; NC, negative control.

A

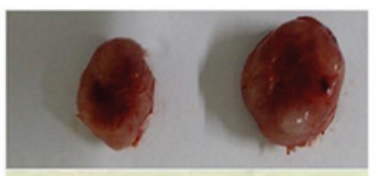

$\begin{array}{lllll}8 & 9 & 10 & 11 & 12\end{array}$

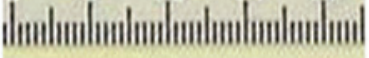

MiR-218 NC
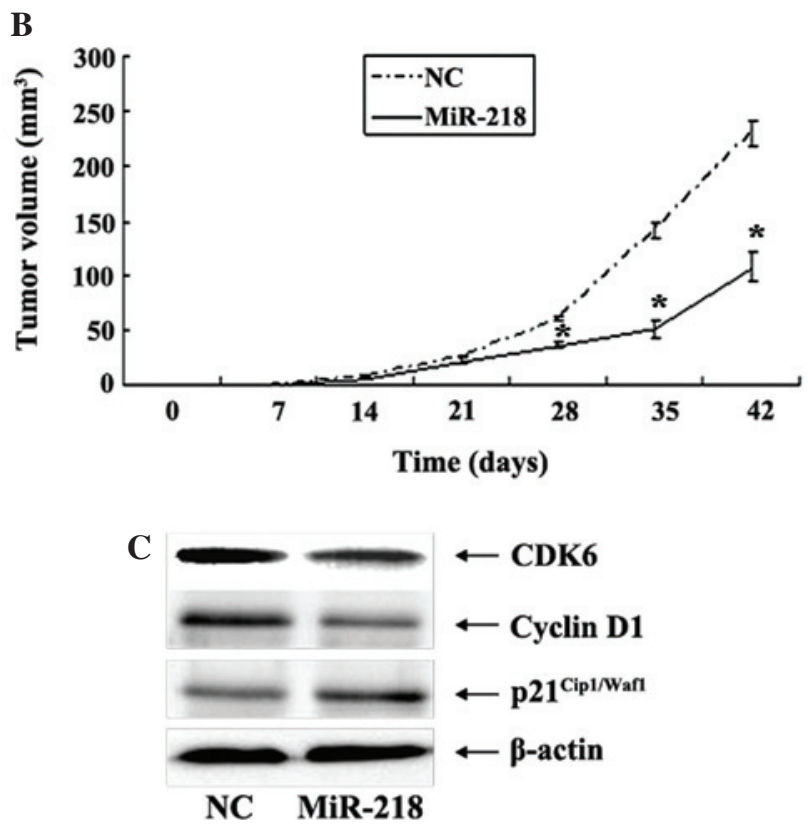

Figure 5. Upregulation of miR-218 suppresses the tumorigenicity of U87 cells in vivo. (A) Representative image of tumor growth. Nude mice were subcutaneously injected with $1.5 \times 10^{6} \mathrm{U} 87$ cells that were stably transfected with miR-218 mimic or mimic NC. (B) Determination of the tumor growth. Tumor volume was calculated every week subsequent to injection. (C) Western blotanalysis of the expression of the CDK6, cyclin D1 and p21 $1^{\mathrm{Cip} / \text { Wafl }}$ proteins in xenograft tumor tissues. The data are presented as the mean + standard deviation from five mice in each group. ${ }^{*} \mathrm{P}<0.05$ vs. NC. miR-218, microRNA-218, $\mathrm{NC}$, negative control; CDK6, cyclin dependent kinase 6. transfected with the miR-218 mimics exhibited an increased accumulation in the $\mathrm{G}_{0}-\mathrm{G}_{1}$ phase with a decreased number of cells in the $\mathrm{S}$ phase (Fig. $4 \mathrm{D}$ ).

Upregulation of miR-218 suppresses tumorigenicity of U87 cells in vivo. To substantiate the role of miR-218 in glioma carcinogenesis, the effects of miR-218 on tumorigenicity of glioma cells were assessed in vivo. Cells that were stably transfected with U87-miR-218 mimic or U87-mimic-NC were implanted into the left flanks of BALB/c athymic mice by subcutaneous injection. At 28 days post-injection, the mean volumes of tumors generated from the miR-218 group were significantly smaller compared with those originating from the NC group (Fig. 5A and B). Western blot analysis of the glioma xenograft tissues revealed that the expression of CDK6 and cyclin D1 was decreased in the xenograft tumor tissues derived from the miR-218 group compared with the NC group. By contrast, the expression of $\mathrm{p} 21^{\text {Cip1/Waf1 }}$ was significantly increased (Fig. 5C).

\section{Discussion}

Rapid and unrestrained cell proliferation is a fundamental component of the malignant phenotype of cancer, not only for the development and growth of primary tumors, but also for the colonization of metastatic tumor cells in their target organs (19). Cell cycle progression involves sequential activation of CDKs, which possess an association with corresponding regulatory cyclins that is necessary for their activation (20). As a critical modulator of the $G_{1}$ to $S$ phase transition, increased expression of cyclin D1 in cancer cells results in an uncontrolled growth advantage. The cyclin D-CDK4/CDK6 and cyclin E-CDK2 complexes regulate cell cycle transition from the $\mathrm{G}_{1}$ to $\mathrm{S}$ phase by phosphorylating and inactivating the retinoblastoma $(\mathrm{Rb})$ protein. However, aberrant activation of the 
cyclin/CDK complexes can be partly ascribed to the loss or inactivation of endogenous CDK inhibitors, including $\mathrm{p} 15^{\mathrm{Ink} 4 \mathrm{~b}}$, p16 ${ }^{\text {Ink4a }}, \mathrm{p} 21^{\text {Cip1/Waf1 }}$ and p27 ${ }^{\text {Kipl }}(21)$. In addition, miR-153 overexpression in prostate cancer cells has been found to increase the expression of the $G_{1} / S$ transitional promoter cyclin 1 and to decrease the expression of the cyclin-dependent kinase (CDK) inhibitor $\mathrm{p} 21^{\mathrm{Cip} 1}$ (22). However, the underlying mechanism that modulates the abundance of the cyclins and CDKs in glioma has yet to be elucidated.

An increasing number of studies have indicated that microRNAs are associated with proliferation and apoptosis by negative regulation of the expression of oncogenes or tumor suppressor genes (23-25). Numerous studies have demonstrated that the expression level of miR-218 is frequently downregulated in several human cancers, including gastric cancer, lung squamous cell carcinoma, malignant astrocytomas and medulloblastomas, which suggests that miR-218 may function as a tumor suppressor (26-28). Previous studies have demonstrated that the ectopic expression of miR-218 contributes to the inhibition of the proliferation, invasion and migration of glioma cells, and induces apoptosis by downregulating the directly targeted gene of miR-218. miR-218 inhibits the expression of target genes that include IKK- $\beta$, and inhibits the expression of NF- $\kappa \mathrm{B}$ in a dose-dependent manner. However, miR-218 also reduces the expression of matrix metalloproteinase-9 (MMP-9) and inhibits the invasive and migratory ability of glioma cells (14). EGFR-coamplified and overexpressed protein (ECOP) has also been identified as a functional downstream target of the genes targeted by miR-218. ECOP is able to regulate the transcriptional activity of NF- $\mathrm{KB}$ and is associated with the apoptotic response. Overexpression of miR-218 restrains the activity of $\mathrm{NF}-\kappa \mathrm{B}$ through the target gene ECOP, thus inducing glioma cell apoptosis and inhibiting the activity, proliferation and tumorigenicity of glioma cells (15). The expression of lymphoid enhancer-binding factor 1 (LEF1) and MMP-9 in the high-grade glioma group was extremely high, while the expression in the low-grade glioma group was extremely low, and the expression of LEF1 and MMP-9 was negatively correlated with the expression of miR-218. Overexpression of miR-218 has been found to inhibit the Wnt/LEF1 signaling pathways that lead to a reduction in MMP-9 synthesis and inhibit tumor invasion (16). The abnormal expression of miR-218 in glioma cells decreased, but abnormal increase CDK6 expression, the expression level of both negatively correlated. Overexpression of miR-218 in glioma cell line can inhibit CDK6 expression and glioma cell proliferation and promote its apoptosis (16).

In the present study, the expression levels of miR-218, CDK6 and $21^{\text {Cip1/Waf } 1}$ were detected in 70 tissue samples obtained from normal brain tissue and low- and high-grade glioma tissues by RT-qPCR and western blot analysis. It was found that the expression of miR-218 and p21 $1^{\text {Cip1/Waf1 }}$ was always inversely associated with the expression of CDK6. Notably, the protein and mRNA levels of CDK6 and cyclin D1 were significantly decreased and the levels of $\mathrm{p} 21^{\mathrm{Cip} 1 / \mathrm{Waf} 1}$ were significantly increased subsequent to the transfection of U87 cells with miR-218 mimics. CDK6 was identified as a direct functional target of miR-218 using bioinformatics analysis, and this finding was experimentally confirmed using a luciferase reporter assay. Therefore, it was found that miR-218 was involved in the modulation of the CDK6/cyclin D1/p21 Cip1/Waf1 pathway and downregulation of CDK6 expression by directly targeting the 3'-UTR of CDK6. In the gain of function investigation, the overexpression of miR-218 was found to inhibit the proliferation of glioma cells proliferation and result in a $G_{0} / G_{1}$ phase arrest of the cell cycle in vitro. miR-218 may also suppress the tumorigenicity of glioma cells in vivo. The results of western blot analysis substantiate that the expression of CDK6 and cyclin D1 in xenograft tumor tissues was significantly decreased. By contrast, the expression of $\mathrm{p} 21^{\mathrm{Cip} 1 / \mathrm{Waf} 1}$ was significantly increased. Overall, the present results indicate that miR-218 inhibits the proliferation of glioma cells through targeting CDK6 to inhibit cyclin D1 activity and activate endogenous CDK inhibitors of p21 $1^{\text {Cipl/Waf1 }}$ activity.

Inconclusion, the presentstudy revealsan associationbetween miR-218-mediated downregulation of glioma cell proliferation and the inactivation of CDK6/cyclin D1/p21 Cip1/Waf1 signaling. The present results suggest that miR-218 is critical for the inhibition of proliferation of glioma cells, and understanding the role of miR-218 may provide important insights into the treatment of gliomas.

\section{References}

1. Yu X, Zhang W, Ning Q and Luo X: MicroRNA-34a inhibits human brain glioma cell growth by down-regulation of Notch1. J Huazhong Univ Sci Technolog Med Sci 32: 370-374, 2012.

2. Van Meir EG, Hadjipanayis CG, Norden AD, Shu HK, Wen PY and Olson JJ: Exciting new advances in neuro-oncology: The avenue to a cure for malignant glioma. CA Cancer J Clin 60: 166-193, 2010.

3. Hou SX, Ding BJ, Li HZ, Wang L, Xia F, Du F, Liu LJ, Liu YH, Liu XD, Jia JF, et al: Identification of microRNA-205 as a potential prognostic indicator for human glioma. J Clin Neurosci 20: 933-937, 2013.

4. Wang R, Jiao Z, Li R, et al: p68 RNA helicase promotes glioma cell proliferation in vitro and in vivo via direct regulation of $\mathrm{NF}-\mathrm{\kappa B}$ transcription factor p50. Neuro Oncol 14: 1116-1124, 2012.

5. Feng SY, Dong CG, Wu WK, et al: Lentiviral expression of anti-microRNAs tar geting miR-27a inhibits proliferation and invasiveness of U87 gliomacells. Mol Med Rep 6: 275-281, 2012.

6. Chan JA, Krichevsky AM and Kosik KS: MicroRNA-21 is an antiapoptotic factor in human glioblastoma cells. Cancer Res 65: 6029-6033, 2005.

7. Bartel DP: MicroRNAs: Target recognition and regulatory functions. Cell 136: 215-233, 2009.

8. Long JM and Lahiri DK: Advances in microRNA experimental approaches to study physiological regulation of gene products implicated in CNS disorders. Exp Neurol 235: 402-418, 2012

9. Park S and James CD: ECop (EGFR-coamplified and overexpressed protein), a novel protein, regulates NF-kappaB transcriptional activity and associated apoptotic response in an IkappaBalpha-dependent manner. Oncogene 24: 2495-2502, 2005.

10. Xu B, Hsu PK, Karayiorgou M and Gogos JA: MicroRNA dysregulation in neuropsychiatric disorders and cognitive dysfunction. Neurobiol Dis 46: 291-301, 2012.

11. Godlewski J, Nowicki MO, Bronisz A, Williams S, Otsuki A, Nuovo G, Raychaudhury A, Newton HB, Chiocca EA and Lawler S: Targeting of the Bmi-1 oncogene/stem cell renewal factor by microRNA-128 inhibits glioma proliferation and self-renewal. Cancer Res 68: 9125-9130, 2008.

12. Silber J, Lim DA, Petritsch C, Persson AI, Maunakea AK, Yu M, Vandenberg SR, Ginzinger DG, James CD, Costello JF, et al: miR-124 and miR-137 inhibit proliferation of glioblastoma multiforme cells and induce differentiation of brain tumor stem cells. BMC Med 6: 14, 2008.

13. Rao SAM, Santosh V and Somasundaram K: Genome-wide expression profiling identifies deregulated miRNAs in malignant astrocytoma. Mod Pathol 23: 1404-1417, 2010. 
14. Song L, Huang Q, Chen K, Liu L, Lin C, Dai T, Yu C, Wu Z and Li J: miR-218 inhibits the invasive ability of glioma cells by direct downregulation of IKK- $\beta$. Biochem Biophys Res Commun 402: 135-140, 2010.

15. Xia H, Yan Y, Hu M, et al: MiR-218 sensitizes glioma cells to apoptosis and inhibits tumorigenicity by regulating ECOP-mediated suppression of NF- $\mathrm{KB}$ activity. Neuro Oncol 15: 413-422, 2013

16. Liu Y, Yan W, Zhang W, et al: MiR-218 reverses high invasiveness of glioblastoma cells by targeting the oncogenic transcription factor LEF1. Oncol Rep 28: 1013-1021, 2012.

17. Zhang JM, Sun CY, Yu SZ, et al: Relationship between miR-218 and CDK6 expression and their biological impact on glioma cell proliferation and apoptosis. Zhonghua Bing Li Xue Za Zhi 40: 454-459, 2011 (In Chinese).

18. Louis DN, Ohgaki H, Wiestler OD, et al: The 2007 WHO classification of tumours of the central nervous system. Acta Neuropathol 114: 97-109, 2007.

19. Cai J, Wu J, Zhang H, Fang L, Huang Y, Yang Y, Zhu X, Li R and Li M: miR-186 downregulation correlates with poor survival in lung adenocarcinoma, where it interferes with cell-cycle regulation. Cancer Res 73: 756-766, 2013.

20. Molinari M: Cell cycle checkpoints and their inactivation in human cancer. Cell Prolif 33: 261-274, 2000.

21. Sherr CJ and Roberts JM: CDK inhibitors: Positive and negative regulators of G1-phase progression. Genes Dev 13: 1501-1512, 1999.
22. Wu Z, He B, He J and Mao X: Upregulation of miR-153 promotes cell proliferation via downregulation of the PTEN tumor suppressor gene in human prostate cancer. Prostate 73: 596-604, 2013.

23. Jovanovic M and Hengartner MO: miRNAs and apoptosis: RNAs to die for. Oncogene 25: 6176-6187, 2006.

24. Xiao B, Tan L, He B, et al: MiRNA-329 targeting E2F1 inhibits cell proliferation in glioma cells. J Transl Med 11: 172, 2013.

25. Kent OA and Mendell JT: A small piece in the cancer puzzle: microRNAs as tumor suppressors and oncogenes. Oncogene 25: 6188-6196, 2006.

26. Martinez I, Gardiner AS, Board KF, Monzon FA, Edwards RP and Khan SA: Human papillomavirus type 16 reduces the expression of microRNA-218 in cervical carcinoma cells. Oncogene 27: 2575-2582, 2008.

27. Petrocca F, Visone R, Onelli MR, Shah MH, Nicoloso MS, de Martino I, Iliopoulos D, Pilozzi E, Liu CG, Negrini M, et al: E2F1-regulated microRNAs impair TGFbeta-dependent cell-cycle arrest and apoptosis in gastric cancer. Cancer Cell 13: 272-286, 2008.

28. Yanaihara N, Caplen N, Bowman E, Seike M, Kumamoto K Yi M, Stephens RM, Okamoto A, Yokota J, Tanaka T, et al: Unique microRNA molecular profiles in lung cancer diagnosis and prognosis. Cancer Cell 9: 189-198, 2006. 